\title{
Miscarriages in families with an offspring that have classic congenital adrenal hyperplasia and 21-hydroxylase deficiency
}

\author{
Helmuth G. Dörr ${ }^{1 *} \mathbb{D}$, Johannes Hess ${ }^{1}$, Theresa Penger ${ }^{1}$, Michaela Marx and Patricia Oppelt ${ }^{2}$
}

\begin{abstract}
Background: The most common form of congenital adrenal hyperplasia is 21-hydroxylase deficiency (CAH). Both men and women with classic CAH have lower fertility rates than the general population, and an increased rate of miscarriages has been reported in affected women. There are no data on the incidence rate of miscarriages in families with an offspring that have classic $\mathrm{CAH}$.

Methods: We studied families with a history of classic CAH. The families came from different parts of Germany and attended the annual meeting of the German CAH support group for parents and patients which was held in Hamburg in September 2014. The data was collected anonymously by a paper-based questionnaire which was completed by the families at home. The families also accepted the responsibility to address this question to their siblings. In all, the data of 50 families with at least one child with classic $\mathrm{CAH}$, and the data of 164 parental siblings were available for evaluation. Miscarriage rates were calculated in relation to the reported pregnancies.
\end{abstract}

Results: Twenty-two miscarriages were reported from 19 families. At least one miscarriage occurred in 38\% of the families, three families experienced two miscarriages and 16 families had one miscarriage each. The mean miscarriage rate was 15.8\%. The heterozygous mothers had a total of 90 siblings ( $41 \mathrm{~m}, 49 \mathrm{f}$ ), while 74 siblings ( $33 \mathrm{~m}, 41 \mathrm{f}$ ) were reported from the heterozygous fathers. The miscarriage rate was $10.1 \%$ in the families of the mothers' siblings, and $11.4 \%$ in the families of the fathers' siblings. The genotype was known in all parents that have an offspring with classic $\mathrm{CAH}$, but not defined in $82 \%$ of the maternal siblings, and in $86 \%$ of the paternal siblings. No child with classic CAH has been diagnosed in any of the sibling's families to date.

Conclusion: Our data show that the miscarriage rate in German families with a child with classic CAH is not elevated.

Keywords: Classic CAH, Miscarriage rate, Offspring with $\mathrm{CAH}$

\section{Background}

Miscarriage is the most common complication of early pregnancy. Among women with known pregnancy, the miscarriage rate is about 10 to $20 \%$ [1-4]. For a prospective cohort of couples from Denmark, recruited prior to conception, the mean incidence was $17 \%$ [5]. A study from the USA calculated in a cohort of 344 couples a pregnancy loss of $28 \%$ which was connected to various preconception lifestyle factors [6]. Overall, there are a variety of factors associated with an increased risk for

\footnotetext{
* Correspondence: helmuth-guenther.doerr@uk-erlangen.de

${ }^{1}$ Division Pediatric Endocrinology, Department Pediatrics, University Hospital of Erlangen (Friedrich Alexander-Universität Erlangen-Nürnberg), Loschgestr. 15, 91054 Erlangen, Germany

Full list of author information is available at the end of the article
}

miscarriage including the age of the mother and father, lifestyle factors, and medical conditions such as infections, fetal and maternal diseases [7-10]. Recently, subclinical hypothyroidism was identified as an endocrine risk factor in women before 20 weeks of pregnancy [11].

The most common form of congenital adrenal hyperplasia is 21-hydroxylase deficiency (CAH) due to mutations in the active gene CYP21A2 [12]. The classic form of CAH with salt wasting (SW) or simple virilizing (SV) presents at childbirth, whereas the nonclassic form of $\mathrm{CAH}(\mathrm{NCAH})$ is generally diagnosed after adolescence. In women with classic $\mathrm{CAH}$, the fertility rate is lower than in the general female population [13, 14], and an increased rate of miscarriages of $36 \%$ has been reported 
in Germany [15] The miscarriage rate in women with $\mathrm{NCAH}$ is somewhat lower than in women with classic $\mathrm{CAH}$. The reported rates vary between 19\% in France $[16,17]$ and $20.3 \%$ in Israel, where this rate was significantly higher than the $10.9 \%$ rate in the general population [18].

To the best of our knowledge, we found no data on the incidence rate of miscarriages in families with an offspring with classic $\mathrm{CAH}$ when both parents are heterozygous gene carriers. Therefore, the objective of this paper was to examine the risk of miscarriages in those families.

\section{Methods}

We studied families with an offspring that have classic congenital adrenal hyperplasia due to 21-hydroxylase deficiency $(\mathrm{CAH})$. The families came from different parts of Germany and attended the annual meeting of the German CAH support group for parents and patients which was held in Hamburg in September 2014. Verbal consent was obtained from all families. The participation at the study was voluntarily. The mothers and the fathers of the participating families also accepted the responsibility to address this question to their siblings. All parental siblings were included in the study, i.e. also single siblings, married siblings and siblings with children without being married. The data was collected anonymously by a paper-based questionnaire (Additional file 1) in accordance with the Declaration of Helsinki. We had no data on the ages of the children and the individual $C Y P 21 A 2$ mutations. The study was approved by the local ethics committee of the Dept. Pediatrics of Erlangen. The questionnaire was completed by the families at home and sent to Erlangen (HGD), where the data was analyzed.

In all, the data of 50 families with at least one child with classic $\mathrm{CAH}$, and the data of 164 parental siblings were available for evaluation. A spontaneous abortion after known pregnancy by the mother was defined as miscarriage. Miscarriage rates were calculated and compared to expected values in the general population. Statistical analysis was performed using SPSS. One-way ANOVA was used to compare miscarriage rates among the parents, sibs of heterozygous females, and sibs of heterozygous males.

\section{Results}

The 50 families had a total of 117 children, including 67 children (57.3\%) with classic CAH (39 girls, 28 boys). There were no children with nonclassic CAH. Most families $(73 \%)$ only had a single child with classic CAH. Twelve families had two affected children, and one family had six children with classic $\mathrm{CAH}$. The age of the parents ranged from 22 to 55 years for the mothers and from 25 to 60 years for the fathers. The male siblings had ages between 18 and 63 years, and the female siblings between 28 and 65 years.

Twenty-two miscarriages, distributed over 19 families, were reported from the families, while 31 families had no miscarriage. This means that at least one miscarriage occurred in $38 \%$ of the interviewed families, three families experienced two miscarriages and 16 families had one miscarriage each. Considering the number of reported miscarriages in relation to the number of clinically recognized pregnancies in the families $(n=139)$, the miscarriage rate was $15.8 \%$.

The genotype was known in all parents that have an offspring with classic $\mathrm{CAH}$, but the parents could not describe the individual mutations. We assume that the children might have genotypes associated with groups null or A, since all children had the severe form of $\mathrm{CAH}$ with salt wasting. The genotype was not defined in $82 \%$ of the maternal siblings, and in $86 \%$ of the paternal siblings.

The heterozygous mothers had a total of 90 siblings (41 brothers, 49 sisters), while 74 siblings (33 brothers, 41 sisters) were reported from the heterozygous fathers. In the siblings with children, the reported miscarriage rate was $10.1 \%$ in the families of the mothers 'siblings, and $11.4 \%$ in the families of the fathers siblings. No child has been diagnosed with classic CAH in any of these families to date.

\section{Discussion}

Women with classic CAH have lower fertility rates compared to general population $[13,14,19,20]$. Recently, this finding was also reported in men with classic $\mathrm{CAH}$ [21]. In women, the causes were assigned to factors such as adrenal overproduction of androgens and progestins, neuroendocrine factors, genital surgery and/or psychosocial factors [22]. However, at this point, one should not confuse the terms fertility and fecundity. Fertility is the natural capability to produce offspring, whereas fecundity is the potential for reproduction of a population. Traditionally, low pregnancy rates have been reported especially in women with classic $\mathrm{CAH}$ and the salt wasting form [23, 24], but recent studies show that the pregnancy rate for all women with classic $\mathrm{CAH}$ who actively tried to conceive was not different from that in the normal population, provided a good biochemical control with optimized glucocorticoid and mineralocorticoid substitution regimens $[19,25]$.

Data on an increased rate of miscarriages in women with classic $\mathrm{CAH}$ is inconsistent in the literature and varied from $10 \%[13,23]$ to $36 \%$ [15]. Women with nonclassic congenital adrenal hyperplasia $(\mathrm{NCAH})$ have also a high rate of miscarriages. The rate of $20.3 \%$ in Israel was higher than in the general population [18], but 
similar to data reported in France before the diagnosis of $\mathrm{NCAH}$ [17]. It is still not clear why a higher miscarriage rate was found in women with classic $\mathrm{CAH}$ and also in women with $\mathrm{NCAH}$. There are many assumptions circulating in the literature but no clear facts. The severity of classic CAH might play a role because Krone et al. identified in their cohort one woman with classic $\mathrm{CAH}$ and salt wasting who had two spontaneous abortions before successful pregnancy [20]. Factors contributing to the lower fertility rate might play a role, too. In particular, adrenal overproduction of androgens due to inadequate glucocorticoid and mineralocorticoid substitution may cause a high rate of spontaneous abortions [22]. In France, the rate of miscarriages in NCAH pregnancies decreased to $10 \%$ in women in whom treatment was started before pregnancy [17] suggesting that therapy may reduce the rate of pregnancy loss in NCAH [26].

Patients with classic CAH suffer from a considerable lifelong burden due to the need for regular physician visits, the risk of adrenal crisis and the long-term impacts of $\mathrm{CAH}$-associated symptoms and treatment [27]. This conclusion applies also for families with a child with classic $\mathrm{CAH}$. Moreover, if a family with a child with $\mathrm{CAH}$ decided on a new pregnancy, then the obligate heterozygous pregnant woman might experience more stress than a normal healthy pregnant woman and must be managed by high-risk practitioners [25, 28]. Reports in the literature show that prenatal stress could be associated with higher rates of spontaneous abortion [29-31]. However, a large study from the USA found no clear pattern of association between stress salivary cortisol and incident pregnancy loss [32].

Overall, data on miscarriages rate in families with a child with classic $\mathrm{CAH}$ when both parents are obligate heterogeneous gene carriers are missing in the literature. We could show that the average miscarriage rate of $15.8 \%$ in families with a classic $\mathrm{CAH}$ child was not different from the rate found in a general population. The miscarriage rates in the siblings' families were lower, but the differences were statistically not significant. There were some limitations to our study. The findings are limited by the nature of the data. The population studied is a selective group of affected families. The data were obtained by a questionnaire from $\mathrm{CAH}$ families who attended the annual meeting of the German CAH Support Group for Patients and Parents, thus the figure of miscarriages might not be representative.

\section{Conclusions}

Our data show that the rate for miscarriages compared to published data in a general population is not elevated, neither in the families with a classic $\mathrm{CAH}$ child nor in the families of the siblings.

\section{Additional file}

Additional file 1: Translated Questionnaire from German Families with an affected child with classic CAH. (DOCX $15 \mathrm{~kb})$

\section{Abbreviations}

CAH: Congenital adrenal hyperplasia; CYP21A2: Cytochrome P450 family 21 subfamily A member 2; F: Female; M: Male; NCAH: Nonclassic congenital adrenal hyperplasia

\section{Acknowledgements \\ The authors are indebted to the German CAH Support Group for Patients and Parents.}

\section{Funding \\ There was no funding.}

Availability of data and materials

We cannot share the raw data because we got no permission from the families.

\section{Authors' contributions}

HGD and PO contributed to the study design. Data collection was performed by $H G D$ and $J H$. HGD, JH, TP, MM and PO were involved in data interpretation and in drafting the manuscript. The final manuscript was prepared by HGD and PO. All authors read and approved the manuscript for publication.

\section{Ethical approval and consent to participate}

The study was approved by the local ethics committee of the Dept. Pediatrics of Erlangen [Professor Dr. Dr. W. Rascher, Dept. Pediatrics, Loschgestr. 15, 91,054 Erlangen. Germany]. The data was collected anonymously by a paper-based questionnaire in accordance with the Declaration of Helsinki and its later amendments. The questionnaire was completed by the families at home and sent by mail or by fax to Erlangen (HGD), where the data was analyzed. Verbal informed consent was obtained from all participating families.

Consent for publication

Not Applicable.

\section{Competing interests}

The authors declare that they have no competing interests.

\section{Publisher's Note}

Springer Nature remains neutral with regard to jurisdictional claims in published maps and institutional affiliations.

\section{Author details}

${ }^{1}$ Division Pediatric Endocrinology, Department Pediatrics, University Hospital of Erlangen (Friedrich Alexander-Universität Erlangen-Nürnberg), Loschgestr. 15, 91054 Erlangen, Germany. ${ }^{2}$ Pediatric Gynecology, Department. Gynecology and Obstetrics, University Hospital of Erlangen, Erlangen, Germany.

Received: 11 April 2018 Accepted: 15 November 2018 Published online: 23 November 2018

\section{References}

1. Warburton D, Fraser FC. Spontaneous abortion risks in man: data from reproductive histories collected in a medical genetics unit. Am J Hum Genet. 1964;16:1-25.

2. Wilcox AJ, Weinberg CR, O'Connor JF, Baird DD, Schlatterer JP, Canfield RE, et al. Incidence of early loss of pregnancy. N Engl J Med. 1988;319(4):189-94.

3. Zinaman MJ, Clegg ED, Brown CC, O'Connor J, Selevan SG. Estimates of human fertility and pregnancy loss. Fertil Steril. 1996;65(3):503-9.

4. Benagiano G, Farris M, Grudzinskas G. Fate of fertilized human oocytes. Reprod BioMed Online. 2010;21(6):732-41.

5. Bonde JP, Hjollund NH, Jensen TK, Ernst E, Kolstad H, Henriksen TB, et al. A follow-up study of environmental and biologic determinants of fertility among 430 Danish first-pregnancy planners: design and methods. Reproductive toxicology (Elmsford, NY) 1998;12(1):19-27. 
6. Buck Louis GM, Sapra KJ, Schisterman EF, Lynch CD, Maisog JM, Grantz KL, et al. Lifestyle and pregnancy loss in a contemporary cohort of women recruited before conception: the LIFE study. Fertil Steril. 2016;106(1):180-8.

7. Pereza N, Ostojic S, Kapovic M, Peterlin B. Systematic review and metaanalysis of genetic association studies in idiopathic recurrent spontaneous abortion. Fertil Steril. 2017;107(1):150-9.e2.

8. Koerten MA, Niwa K, Szatmari A, Hajnalka B, Ruzsa Z, Nagdyman N, et al. Frequency of miscarriage/stillbirth and terminations of pregnancy among women with congenital heart disease in Germany, Hungary and Japan. Circulation journal : official journal of the Japanese circulation. Society. 2016; 80(8):1846-51.

9. Giakoumelou S, Wheelhouse N, Cuschieri K, Entrican G, Howie SE, Horne AW. The role of infection in miscarriage. Hum Reprod Update. 2016;22(1):116-33.

10. Balsells M, Garcia-Patterson A, Corcoy R. Systematic review and metaanalysis on the association of prepregnancy underweight and miscarriage. Eur J Obstet Gynecol Reprod Biol. 2016;207:73-9.

11. Zhang Y, Wang H, Pan X, Teng W, Shan Z. Patients with subclinical hypothyroidism before 20 weeks of pregnancy have a higher risk of miscarriage: a systematic review and meta-analysis. PLoS One. 2017;12(4):e0175708.

12. Auchus RJ. The classic and nonclassic congenital adrenal Hyperplasias. Endocr Pract. 2014:1-25.

13. Hagenfeldt K, Janson PO, Holmdahl G, Falhammar H, Filipsson H, Frisen L, et al. Fertility and pregnancy outcome in women with congenital adrenal hyperplasia due to 21-hydroxylase deficiency. Hum Reprod. 2008;23(7): 1607-13.

14. Strandqvist A, Falhammar H, Lichtenstein P, Hirschberg AL, Wedell A, Norrby C, et al. Suboptimal psychosocial outcomes in patients with congenital adrenal hyperplasia: epidemiological studies in a nonbiased national cohort in Sweden. J Clin Endocrinol Metab. 2014;99(4):1425-32.

15. Remde H, Zopf K, Schwander J, Quinkler M. Fertility and pregnancy in primary adrenal insufficiency in Germany. Horm Metab Res. 2016;48(5):306-11.

16. Moran C, Azziz R, Weintrob N, Witchel SF, Rohmer V, Dewailly D, et al. Reproductive outcome of women with 21-hydroxylase-deficient nonclassic adrenal hyperplasia. J Clin Endocrinol Metab. 2006;91(9):3451-6.

17. Bidet M, Bellanne-Chantelot C, Galand-Portier MB, Golmard JL, Tardy V, Morel $Y$, et al. Fertility in women with nonclassical congenital adrenal hyperplasia due to 21-hydroxylase deficiency. J Clin Endocrinol Metab. 2010; 95(3):1182-90.

18. Eyal O, Ayalon-Dangur I, Segev-Becker A, Schachter-Davidov A, Israel S, Weintrob N. Pregnancy in women with nonclassic congenital adrenal hyperplasia: time to conceive and outcome. Clin Endocrinol. 2017;87(5): 552-6.

19. Casteras A, De Silva P, Rumsby G, Conway GS. Reassessing fecundity in women with classical congenital adrenal hyperplasia (CAH): normal pregnancy rate but reduced fertility rate. Clin Endocrinol. 2009;70(6):833-7.

20. Krone N, Wachter I, Stefanidou M, Roscher AA, Schwarz HP. Mothers with congenital adrenal hyperplasia and their children: outcome of pregnancy, birth and childhood. Clin Endocrinol. 2001;55(4):523-9.

21. Falhammar H, Frisen L, Norrby C, Almqvist C, Hirschberg AL, Nordenskjold A et al. Reduced frequency of biological and increased frequency of adopted children in males with 21-hydroxylase deficiency: a Swedish populationbased National Cohort Study. J Clin Endocrinol Metab. 2017;102(11):4191-9.

22. Mooij CF, Webb EA, Claahsen van der Grinten HL, Krone N. Cardiovascular health, growth and gonadal function in children and adolescents with congenital adrenal hyperplasia. Arch Dis Child. 2017;102(6):578-84.

23. Lo JC, Grumbach MM. Pregnancy outcomes in women with congenital virilizing adrenal hyperplasia. Endocrinol Metab Clin N Am. 2001;30(1):207-29.

24. Mulaikal RM, Migeon CJ, Rock JA. Fertility rates in female patients with congenital adrenal hyperplasia due to 21-hydroxylase deficiency. N Engl J Med. 1987:316(4):178-82

25. Witchel SF. Management of CAH during pregnancy: optimizing outcomes. Curr Opin Endocrinol Diabetes Obes. 2012;19(6):489-96.

26. Carmina E, Dewailly D, Escobar-Morreale HF, Kelestimur F, Moran C, Oberfield S, et al. Non-classic congenital adrenal hyperplasia due to 21hydroxylase deficiency revisited: an update with a special focus on adolescent and adult women. Hum Reprod Update. 2017;23(5):580-99.

27. Hummel SR, Sadler S, Whitaker MJ, Ara RM, Dixon S, Ross RJ. A model for measuring the health burden of classic congenital adrenal hyperplasia in adults. Clin Endocrinol. 2016.

28. Speiser PW. Congenital adrenal hyperplasia. F1000Research. 2015:4(F1000 Faculty Rev):601.
29. Marinescu IP, Foarfa MC, Pirlog MC, Turculeanu A. Prenatal depression and stress - risk factors for placental pathology and spontaneous abortion. Romanian journal of morphology and embryology = Revue roumaine de morphologie et embryologie. 2014;55(3 Suppl):1155-60.

30. Arck PC, Rucke M, Rose M, Szekeres-Bartho J, Douglas AJ, Pritsch M, et al. Early risk factors for miscarriage: a prospective cohort study in pregnant women. Reprod BioMed Online. 2008;17(1):101-13.

31. Nepomnaschy PA, Welch KB, McConnell DS, Low BS, Strassmann BI, England BG. Cortisol levels and very early pregnancy loss in humans. Proc Natl Acad Sci U S A. 2006;103(10):3938-42.

32. Lynch CD, Sundaram R, Buck Louis GM. Biomarkers of preconception stress and the incidence of pregnancy loss. Hum Reprod. 2018.
Ready to submit your research? Choose BMC and benefit from:

- fast, convenient online submission

- thorough peer review by experienced researchers in your field

- rapid publication on acceptance

- support for research data, including large and complex data types

- gold Open Access which fosters wider collaboration and increased citations

- maximum visibility for your research: over $100 \mathrm{M}$ website views per year

At BMC, research is always in progress.

Learn more biomedcentral.com/submissions 